\title{
Utilidad clínica de la procalcitonina en gastroenteritis aguda
}

\author{
ANA BELÉN MARTÍNEZ L. ${ }^{1}$, , RAFAEL MARAÑÓN P. ${ }^{1}$, PILAR VIRGINIA COBO E. ${ }^{1}$, \\ CRISTINA TOMATIS S. ${ }^{1}$, LUIS GUERRA M. ${ }^{1}$, ANA CRISTINA PEÑALBA C. ${ }^{1}$ \\ 1. Pediatría. Sección de Urgencias Pediátricas. Hospital General Universitario Gregorio Marañón, Madrid, España.
}

\begin{abstract}
Use of procalcitonin as diagnostic marker in acute gastroenteritis

Introduction: There is no hematological marker that reliably differentiates between bacterial and nonbacterial acute gastroenteritis (AGE). The objective of this study is to evaluate procalcitonin (PCT) as a marker for bacterial AGE and analyze its relationship with hospital admission. Patients and Method: A prospective study of children diagnosed with AGE was conducted at the emergency room during a period of seven months, which required blood and stool samples. Epidemiological, clinical and analytical variables were analyzed. Patients with chronic digestive disease, prolonged diarrhea, immunodeficiency or prior antibiotic treatment were excluded. The study was approved by the Ethics Committee and an informed consent was requested. Results: 45 patients were analyzed. Children with bacterial GEA were older $(\mathrm{p}=0.027)$ and presented higher median PCT and C-reactive protein concentrations $(\mathrm{CRP})(\mathrm{p}=0.001)$. The PCT and CRP values that best discriminated bacterial infection were PCT $\geq 0.05 \mathrm{mg} / \mathrm{L}$ (sensibility $64.3 \%$, specificity $83.9 \%$, positive probability coefficient (PPC): 4), and CRP $\geq 3 \mathrm{mg} / \mathrm{dL}$ (sensibility 78.6\%, specificity 90.3\%, PPC: 8 ). No association between the elevation of these markers and higher hospitalization probability was found. Conclusion: Procalcitonin, like $\mathrm{CRP}$, is elevated in bacterial gastroenteritis $(\mathrm{p}=0.001)$, but these markers are not a predictor of hospitalization.
\end{abstract} (Key words: Acute gastroenteritis, procalcitonin, C-reactive protein, bacteria, virus).

Rev Chil Pediatr 2014; 85 (2): 157-163

\section{RESUMEN}

Introducción: No hay ningún marcador hematológico que diferencie con seguridad entre gastroenteritis aguda (GEA) bacteriana y no bacteriana. Nuestro objetivo fue evaluar la procalcitonina (PCT) como marcador de GEA de origen bacteriano y analizar su correlación con el ingreso hospitalario. Pacientes y Método: Estudio prospectivo de niños diagnosticados de GEA en el departamento de Urgencias durante un período de 7 meses que requirieron de analítica sanguínea y muestras de heces. Se analizaron variables epidemiológicas, clínicas y analíticas. Se excluyeron pacientes con enfermedad digestiva crónica, diarrea prolongada, inmunodeficiencia

Recibido el 9 de octubre de 2012, devuelto para corregir el 12 de marzo de 2013, segunda versión 20 de junio de 2013, tercera versión 16 de septiembre de 2013, aceptado para publicación el 15 de octubre de 2013.

Este trabajo cumple con los requisitos sobre consentimiento /asentimiento informado, comité de ética, financiamiento, estudios animales y sobre la ausencia de conflictos de intereses según corresponda.

Correspondencia a:

Ana Belén Martínez López

E-mail: anabelenml_8@hotmail.com 
o tratamiento antibiótico previo. El estudio fue aprobado por el Comité de Ética y se solicitó consentimiento informado. Resultados: Se analizaron 45 pacientes. Los niños con GEA bacteriana tenían mayor edad ( $\mathrm{p}=$ $0,027)$, mayor mediana de PCT y proteína $C$ reactiva $(P C R)(p=0,001)$. Los valores de PCT y PCR que mejor discriminaron la etiología bacteriana fueron PCT $\geq 0,5 \mathrm{mg} / \mathrm{L}$ (sensibilidad: $64,3 \%$, especificidad: $83,9 \%$, cociente de probabilidad positivo (CPP): 4) y PCR $\geq 3 \mathrm{mg} / \mathrm{dL}$ (sensibilidad: 78,6\%, especificidad: 90,3\%, CPP: 8). No se encontró asociación entre la elevación de dichos marcadores y una mayor probabilidad de hospitalización. Conclusión: La procalcitonina, al igual que la PCR, se eleva en gastroenteritis bacterianas $(p=0,001)$, no siendo estos marcadores predictores de hospitalización.

(Palabras clave: Gastroenteritis Aguda, Procalcitonina, Proteína C Reactiva, Bacteria, Virus).

Rev Chil Pediatr 2014; 85 (2): 157-163

\section{Introducción}

La gastroenteritis aguda (GEA) es uno de los diagnósticos más frecuentes en Servicios de Urgencia Pediatricos ${ }^{1}$ (Urgencias) y representa una causa importante de morbilidad infantil, principalmente en países subdesarrollados $^{2}$. Los procesos víricos son los principales responsables, sin embargo, enfermedades bacterianas o procesos sistémicos pueden cursar con diarrea aguda como principal manifestación. La presentación clínica de la GEA es variable, desde casos con sintomatología leve hasta pacientes con deshidratación grave.

Debido a la dificultad de predecir una evolución desfavorable cuando el paciente es valorado al inicio del cuadro, sumado a la demora en el diagnóstico que requiere el procesamiento de los cultivos de heces, se ha evaluado la utilidad de diferentes marcadores hematológicos para determinar el pronóstico de la enfermedad cuando el paciente acude a Urgencias. La orientación etiológica adquiere una mayor importancia en procesos de mayor gravedad, diarreas enteroinvasivas o pacientes inmunocomprometidos, pacientes en los que el tratamiento antimicrobiano específico precoz reduce la duración del proceso y disminuye su morbilidad y mortalidad ${ }^{3}$. Del mismo modo, el diagnóstico precoz de una GEA de origen bacteriano permite tomar medidas para disminuir su transmisión y es fundamental para una precoz notificación y detección de brotes epidémicos ${ }^{3}$. Hasta el momento no se ha identificado ningún marcador hematológico que diferencie con seguridad entre GEA bacteriana y no bacteriana ${ }^{4}$, pero la presencia de un ma- yor recuento de neutrófilos en banda o cayados $\left(>100 / \mathrm{mm}^{3}\right)$, la elevación en la razón cayados/ neutrófilos, o la presencia de una proteína $\mathrm{C}$ reactiva $(\mathrm{PCR})>12 \mathrm{mg} / \mathrm{dL}$, se han relacionado con la aparición de bacterias patógenas en el coprocultivo.

Estudios previos de procalcitonina han objetivado una mayor especificidad pero una menor sensibilidad en la identificación de GEA bacteriana en comparación con la $\mathrm{PCR}^{5,6}$. $\mathrm{La}$ procalcitonina (PCT) es la prohormona de la calcitonina. Se sintetiza en las células $\mathrm{C}$ del tiroides, para convertirse en la hormona activa. Es prácticamente indetectable en individuos sanos, elevándose significativamente en estados inflamatorios de origen bacteriano ${ }^{7,8}$.

Los objetivos del estudio han sido evaluar la PCT como marcador de GEA de origen bacteriano y analizar su correlación con el ingreso o admisión hospitalaria.

\section{Pacientes y Método}

Estudio prospectivo para determinar la capacidad discriminatoria de la PCT en el diagnóstico de la GEA de origen bacteriano en la sección de Urgencias de Pediatría del Hospital General Universitario Gregorio Marañón durante 7 meses (01 de julio de 2011 al 30 de enero de 2012), donde se incluyeron pacientes de 1 mes a 16 años con diagnóstico de GEA que precisaron, según la valoración por el facultativo de guardia, realizar analítica de sangre y recoger muestras de heces para realizar coprocultivo y estudio de antígenos virales (rotavirus y adenovirus). Se incluyeron a los 
10 primeros pacientes de cada mes que cumplieron criterios de inclusión y cuyos padres o tutores legales firmaron el consentimiento informado que se solicitó para participar en el estudio. El estudio fue aprobado por el Comité de Ética e Investigación Clínica del hospital. Se excluyeron pacientes con enfermedad digestiva crónica, diarrea prolongada o crónica, pacientes inmunodeprimidos y aquellos que habían recibido tratamiento antibiótico los siete días previos.

Se recogieron variables epidemiológicas (edad y sexo), variables clínicas como el tiempo de evolución de la diarrea, sangre en heces, vómitos, número de deposiciones y de vómitos en las últimas 24 h, fiebre, temperatura máxima, ambiente epidémico (otros familiares o contactos cercanos con mismo cuadro clínico), presencia y grado de deshidratación siguiendo la puntuación de la Academia Americana de Pediatría ${ }^{9}$, necesidad de admisión al hospital, y tiempo de duración del ingreso; y variables analíticas, como leucocitos y polimorfonucleares, PCR, PCT, creatinina, urea, coprocultivo $\mathrm{y}$ antígenos de rotavirus y adenovirus en heces.

\section{Definiciones}

GEA: disminución de la consistencia de las heces (blandas o líquidas) y/o aumento en la frecuencia de las deposiciones ( $\geq 3$ en 24 h), con o sin fiebre o vómitos y una duración inferior a 14 días $^{3}$. GEA bacteriana: crecimiento de uno o más patógenos en el coprocultivo considerado como el gold estándar de diagnóstico o la detección mediante cultivo toxigénico y citotoxicidad directa en el caso de Clostridium difficile. Para el diagnostico de GEA viral consideramos el gold estándar la presencia de antígeno de rotavirus o adenovirus en las heces. GEA indeterminada si los estudios previos eran negativos.

La PCT se determinó mediante inmunoensayo "ECLIA" de electro quimioluminiscencia (Elecsys ${ }^{\circledR}$ BRAHMS-PCT). En nuestro laboratorio el límite inferior de PCR es $0,1 \mathrm{mg} / \mathrm{dL}$ y de PCT $0,1 \mathrm{mg} / \mathrm{L}(=0,1 \mathrm{ng} / \mathrm{mL})$. Se realizó determinación antigénica de rotavirus y adenovirus mediante inmunocromatografía (Simple Rota-Adeno Operon $\left.{ }^{\circledR}\right)$. Los cultivos de heces se realizaron en los medios Agar Salmonella shigella, Agar Ampicilina, Agar Campylobacter y caldo de selenito como medio líquido de enriquecimiento. Se utilizó el cultivo toxigénico y la citotoxicidad directa de las heces para el diagnóstico de Clostridium difficile ${ }^{10}$.

El análisis estadístico se realizó con el programa informático SPSS.16. Los datos referentes a variables cuantitativas se presentan como medianas (p25-p75) y las variables cualitativas como porcentajes. Para comparar grupos se emplearon los test de $\chi^{2}$, U de Mann-Whitney y la prueba de Kruskal Wallis. Se consideró significativo un valor de $p<0,05$. Se construyó una curva ROC para determinar qué valor de PCT y de PCR se correlacionaba mejor con el origen bacteriano y se calculó sensibilidad (S), especificidad (E), valor predictivo positivo (VPP) y negativo (VPN) así como el cociente de probabilidad positivo (CPP).

\section{Resultados}

En el período de estudio se realizaron 2.192 diagnósticos de GEA en Urgencias. Ingresaron 119 pacientes $(5,4 \%)$. Firmaron el consentimiento informado 68 pacientes, 23 de ellos fueron excluidos y se analizaron finalmente 45 pacientes. La selección de pacientes se muestra en la figura 1. La mediana de edad fue de 25 meses (11-66), predominio de varones $(71,1 \%)$. La mediana del tiempo de evolución hasta acudir a Urgencias fue de 48 h (18-96), y cuando acudieron un $49 \%$ presentaba una deshidratación leve. Ingresaron en el hospital el $86,7 \%$ de los pacientes. Todos los hemocultivos realizados resultaron negativos.

Al analizar las características demográficas, clínicas y analíticas entre los pacientes con GEA de origen bacteriano y aquellos de causa no bacteriana (GEA vírica e indeterminada) observamos que los niños con GEA bacteriana tenían mayor edad $(\mathrm{p}=0,027)$ y la mediana de PCT y PCR eran mayor $(\mathrm{p}=0,001)$. No se encontraron diferencias significativas en los síntomas de presentación (tabla 1).

Al analizar separadamente los tres grupos se observó que los pacientes con GEA bacteriana presentaban con mayor frecuencia sangre en las heces y los pacientes con GEA vírica 
Total diagnósticos de GEA en el período de estudio: 2.192

68 pacientes seleccionados

23 pacientes excluidos

\begin{tabular}{|l|l|}
\hline 2 pacientes & No realizada PCT \\
\hline 2 pacientes & $\begin{array}{l}\text { Antígeno rotavirus positivo y coprocul- } \\
\text { tivo positivo }\end{array}$ \\
\hline 19 pacientes & $\begin{array}{l}\text { Muestras de heces incompletas (falta } \\
\text { coprocultivo o antígenos virales o no } \\
\text { realizan deposición durante su estancia) }\end{array}$ \\
\hline
\end{tabular}

45 pacientes incluidos

- 14 pacientes (31\%): GEA bacteriana
\begin{tabular}{|l|l|}
\hline 7 pacientes & Salmonella \\
\hline 5 pacientes & Campylobacter \\
\hline 1 paciente & Clostridium difficile no toxigénico \\
\hline 1 paciente & Clostridium difficile toxigénico \\
\hline
\end{tabular}

- 13 pacientes (29\%): GEA vírica

\begin{tabular}{|l|l|}
\hline 11 pacientes & Rotavirus \\
\hline 2 pacientes & Adenovirus \\
\hline
\end{tabular}

- 18 pacientes (40\%): GEA indeterminada

Figura 1. Selección de los pacientes y etiología GEA. GEA: gastroenteritis aguda.

Tabla 1. Características demográficas, clínicas y analíticas entre los pacientes con gastroenteritis bacteriana y aquellos de causa no bacteriana

\begin{tabular}{|c|c|c|c|}
\hline & \multicolumn{3}{|c|}{ Gastroenteritis aguda } \\
\hline & Bacteriana $(n=14)$ & No bacteriana $(n=31)$ & $\mathbf{p}$ \\
\hline Edad en meses (mediana p25-p75) & $43,0(22,7-82,7)$ & $18,0(9,0-62,0)$ & 0,027 \\
\hline Sexo varón, \% & 57,1 & 77,4 & 0,286 \\
\hline Tiempo de evolución en h (mediana p25-p75) & $48(20-96)$ & $48(12-96)$ & 0,901 \\
\hline n deposiciones últimas 24 h, (mediana p25-p75) & $8,0(5-18)$ & $8(5-13)$ & 0,931 \\
\hline Presencia de sangre en heces, \% & 35,7 & 9,7 & 0,085 \\
\hline n vómitos últimas 24 h, (mediana p25-p75) & $5(3-7)$ & $4(2-16)$ & 0,833 \\
\hline Ambiente epidémico de GEA, \% & 21,4 & 29,0 & 0,725 \\
\hline $\begin{array}{l}\text { Temperatura máxima }{ }^{\circ} \mathrm{C}, \\
\text { (mediana p25-p75) }\end{array}$ & $39,0(38,4-39,1)$ & $38,6(38,0-39,1)$ & 0,262 \\
\hline $\begin{array}{l}\text { Deshidratación, \% } \\
\text { Leve } \\
\text { Moderada }\end{array}$ & $\begin{array}{l}64,3 \\
21,4\end{array}$ & $\begin{array}{l}41,9 \\
51,6\end{array}$ & $\begin{array}{l}0,286 \\
0,116\end{array}$ \\
\hline Leucocitos totales $/ \mathrm{mm}^{3}$, (mediana p25-p75) & $9.150(8.300-15.025)$ & $10.900(8.100-14.800)$ & 0,545 \\
\hline Neutrófilos totales $/ \mathrm{mm}^{3}$, (mediana p25-p75) & $6.350(4.523-12.470)$ & $6.572(3.377-11.618)$ & 0,154 \\
\hline PCR mg/dL (mediana p25-p75) & $4,9(2,5-11,9)$ & $0,2(0,1-1,8)$ & 0,001 \\
\hline PCT mg/L (mediana p25-p75) & $0,6(0,2-2,0)$ & $0,1(0,1-0,3)$ & 0,001 \\
\hline Ingreso, \% & 78,6 & 90,3 & 0,356 \\
\hline
\end{tabular}

GEA: gastroenteritis aguda. PCR: Proteína C Reactiva. PCT: Procalcitonina. 
presentaban mayor número de vómitos, y mayor porcentaje de deshidratación moderada, si bien estos resultados no fueron estadísticamente significativos (tabla 2).

Por último, se determinaron los valores de PCT y de PCR que mejor discriminaban la etiología bacteriana de la GEA. La figura 2 muestra la curva ROC para $\mathrm{PCT} \geq 0,5 \mathrm{mg} / \mathrm{L}$ y $\mathrm{PCR} \geq 3,0$ $\mathrm{mg} / \mathrm{dL}$. Un valor de $\mathrm{PCT} \geq 0,5 \mathrm{mg} / \mathrm{L}$ presentó
S del 64,3\% (35,6-92,6), E del 83,9\% $(69,3-$ $98,4)$, VPP $64,3 \%(35,6-92,6)$ y VPN $83,9 \%$ $(69,3-98,4)$ con un CPP de 4 (1,6-9,7). Un valor de $\mathrm{PCR} \geq 3 \mathrm{mg} / \mathrm{dL}$ presentó $\mathrm{S}$ del $78,6 \%$ (53,5-100), E 90,3\% (78,3-100), VPP 78,6\% (53,5-100), VPN 90,3\% (78,3-100) y CPP de $8(2,7-24,6)$. No encontramos asociación entre PCT $\geq 0,5$ e ingreso hospitalario $(p=0,356) n i$ entre PCR $\geq 3$ e ingreso $(p=1)$.

Tabla 2. Comparación de características demográficas, clínicas y analíticas entre los tres grupos de gastroenteritis aguda

\begin{tabular}{|c|c|c|c|}
\hline & \multicolumn{3}{|c|}{ Estratificación por grupos según la etiología } \\
\hline & $\begin{array}{l}\text { Bacteriana } \\
(n=14)\end{array}$ & $\begin{array}{l}\text { Vírica } \\
(n=13)\end{array}$ & $\begin{array}{l}\text { Indeterminada } \\
(n=18)\end{array}$ \\
\hline Edad en meses (mediana) & $43(23-83)$ & $11(11-21)$ & $25(11-99)$ \\
\hline $\begin{array}{l}\text { Género } \\
\text { Masculino, n; \% } \\
\text { Femenino, n; \% }\end{array}$ & $\begin{array}{l}8 ; 57,1 \\
6 ; 42,9\end{array}$ & $\begin{array}{l}11 ; 84,6 \\
2 ; 15,4\end{array}$ & $\begin{array}{l}13 ; 72,2 \\
5 ; 27,8\end{array}$ \\
\hline $\begin{array}{l}\text { Duración diarrea hasta la visita a Urgencias } h \\
\text { media } \pm \text { DS } \\
\text { mediana (p25-p75) }\end{array}$ & $\begin{array}{c}54 \pm 38 \\
48(20-96)\end{array}$ & $\begin{array}{c}49 \pm 30 \\
48(30-48)\end{array}$ & $\begin{array}{l}81 \pm 117 \\
48(6-102)\end{array}$ \\
\hline $\begin{array}{l}\mathrm{n} \text { deposiciones últimas } 24 \mathrm{~h} \text {, } \\
\text { mediana (p25-p75) }\end{array}$ & $8(5-18)$ & $10(6-14)$ & $7(5-12)$ \\
\hline Sangre en heces, \% & 35,7 & 0 & 16,7 \\
\hline Presencia vómitos, \% & 64,3 & 76,9 & 72,2 \\
\hline $\begin{array}{l}\text { No vómitos últimas } 24 \text { h, } \\
\text { - mediana (p25-p75) }\end{array}$ & $5(3-7)$ & $10(3-16)$ & $4(2-9)$ \\
\hline $\begin{array}{l}\mathrm{T}^{\circ} \text { máxima, }{ }^{\circ} \mathrm{C} \\
\text { - mediana (p25-p75) }\end{array}$ & $39,0(38,4-39,1)$ & $38,5(38,0-39,1)$ & $38,7(38,1-39,4)$ \\
\hline Ambiente epidémico, \% & 21,4 & 23,1 & 33,3 \\
\hline $\begin{array}{l}\text { Deshidratación, \% } \\
\text { Leve } \\
\text { Moderada }\end{array}$ & $\begin{array}{l}64,3 \\
21,4\end{array}$ & $\begin{array}{l}23,1 \\
61,5\end{array}$ & $\begin{array}{l}55,6 \\
44,4\end{array}$ \\
\hline $\begin{array}{l}\text { Leucocitos por } \mathrm{mm}^{3} \\
\text { mediana (p25-p75) }\end{array}$ & $9.150(8.300-15.025)$ & $10.550(8.225-15.500)$ & $11.050(7.675-14.975)$ \\
\hline $\begin{array}{l}\text { Polimorfonucleares, \% } \\
\text { mediana (p25-p75) }\end{array}$ & $69,4(55,2-81,4)$ & $51,45(38,2-64,45)$ & $62,9(43,3-80,8)$ \\
\hline $\begin{array}{l}\mathrm{PCR}, \mathrm{mg} / \mathrm{dL} \\
\text { mediana (p25-p75) }\end{array}$ & $4,9(2,5-11,9)$ & $0,5(0,1-2,1)$ & $0,5(0,1-1,8)$ \\
\hline $\begin{array}{l}\mathrm{PCT}, \mu \mathrm{g} / \mathrm{L} \\
\text { mediana (p25-p75) }\end{array}$ & $0,6(0,2-2,0)$ & $0,1(0,1-0,3)$ & $0,1(0,1-0,3)$ \\
\hline Ingreso, \% & 78,6 & 100 & 83,3 \\
\hline $\begin{array}{l}\text { Estancia media, días } \\
\text { mediana (p25-p75) }\end{array}$ & $4(4-7)$ & $3(2-4)$ & $3(2-4)$ \\
\hline
\end{tabular}

PCR: Proteína C Reactiva. PCT: Procalcitonina. 


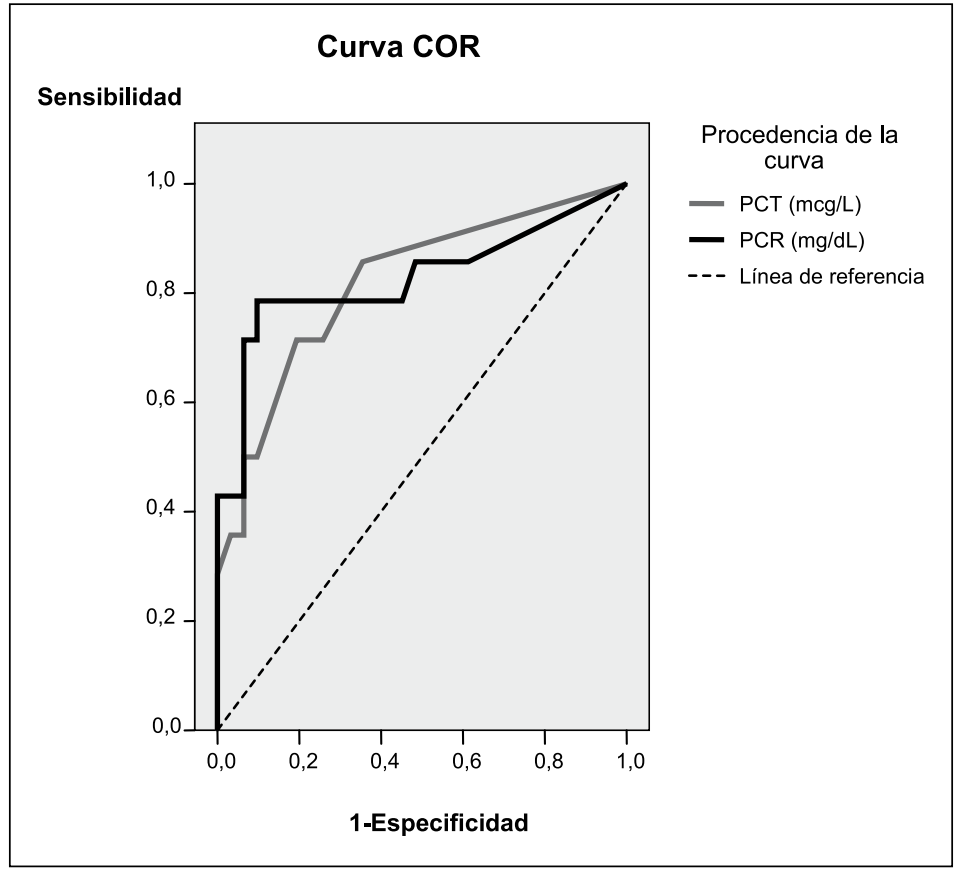

Figura 2. Curva ROC. PCT $\geq 0,5 \mu \mathrm{g} / \mathrm{L}$ y $\mathrm{PCR} \geq 3 \mathrm{mg} / \mathrm{dL}$ con respecto a la etiología bacteriana de la gastroenteritis aguda utilizando el coprocultivo como gold stándar de diagnóstico (área bajo la curva PCT $0,818$ y PCR 0,826$)$. PCT: Procalcitonina. PCR: Proteína C Reactiva.

\section{Discusión}

Coincidiendo con lo publicado, el rotavirus fue el agente causal más frecuente ${ }^{4}$ con una mediana de edad de 11 meses. Entre los agentes bacterianos (más frecuentes a partir de los 4 años de edad), destacan Salmonella y Campylobacter ${ }^{4,11,12}$.

Se ha visto que los síntomas clínicos no predicen una causa bacteriana o viral, aunque hay algunas manifestaciones que son más frecuentes en cada grupo. Los pacientes con gastroenteritis vírica presentan mayor número de vómitos así como mayor grado de deshidratación ${ }^{4}$. En nuestro grupo la diferencia no fue significativa, probablemente por el número de pacientes analizados. Referente a la presencia de sangre en heces en relación con la etiología bacteriana, Finkelstein et al, obtuvieron un VPN de $0,91^{13}$. En nuestro estudio el 35,7\% de las GEA bacterianas la presentaron, sin embargo, ninguna de las GEAS virales tenían sangre en heces.

No se encontró relación entre el recuento de leucocitos o polimorfonucleares y la GEA bacteriana. Estudios anteriores han determina- do la utilidad de la medición de PCR para predecir un cultivo bacteriano en heces positivos, Borgnolo et al, obtuvieron que con un valor $>12 \mathrm{mg} / \mathrm{dl}$, la PCR tiene una sensibilidad del $77 \%$, especificidad del $89 \%$, VPP $91 \%$, VPN $72 \%$ y eficacia diagnóstica de $0,83^{14}$. El estudio de Korczowski et al, determinó que la PCT es más específica pero menos sensible que la PCR para distinguir una causa bacteriana ${ }^{5}$. En el estudio de Thia et al, concluyeron que PCT y PCR son los mejores marcadores hematológicos para predecir la etiología bacteriana de GEA (área bajo la curva de 0,73 y 0,79 , respectivamente) y que PCT era más específica; con un punto de corte de PCT $\geq 0,5 \mathrm{ng} / \mathrm{ml}$, la sensibilidad de GEA bacteriana fue de un $40 \%$ (95\% CI 20-64) con $92 \%$ de especificidad $\left(95 \%\right.$ CI 84-87) ${ }^{6}$; nuestro estudio mostró una sensibilidad mayor $(64,3 \%)$ con especificidad algo menor $(83,9 \%)$.

En este estudio el tamaño muestral fue pequeño y se realizó en un solo centro, lo cual podría significar que los resultados no sean generalizables, si bien son similares a estudios previos. La necesidad de realización de analítica sanguínea para la inclusión en el estudio 
justifica la gran proporción de pacientes que requiere ingreso hospitalario $(86,7 \%)$ en comparación con el total de pacientes diagnosticados de GEA durante ese período que lo precisaron $(5,4 \%)$, lo cual está condicionado por la mayor probabilidad que a priori tienen estos pacientes de ingresar dada la situación en la que acuden.

Concluimos que la PCT se eleva en las GEA bacterianas $(\mathrm{p}=0,001)$, no obstante la PCR también se eleva $(\mathrm{p}=0,001) \mathrm{y}$, puesto que la mediana del tiempo en consultar en Urgencias es de $48 \mathrm{~h}$ para todos los grupos y el costo económico de la PCR es menor, no estaría aconsejado según nuestros datos realizar PCT. Por otra parte, ni PCT así como tampoco PCR son predictores de la necesidad de ingreso hospitalario, siendo el diagnóstico clínico y la evaluación del estado de hidratación las piedras angulares para decidir necesidad de ingreso hospitalario.

\section{Agradecimientos}

A José María Bellón por su ayuda en el análisis estadístico y a todas las personas que trabajan en la Sección de Urgencias de nuestro hospital que, de una forma u otra, han contribuido a la realización de este trabajo.

\section{Referencias}

1.- Grupo de trabajo de codificación diagnóstica: Sociedad Española de Urgencias de Pediatría. Codificación diagnóstica en urgencias de Pediatría. An Esp Pediatr 2000; 53: 261-72.

2.- Filho EP, Da Costa Faria NR, Fialho AM, et al: Adenoviruses associated with acute gastroenteritis in hospitalized and community children up to 5 years old in Rio de Janeiro and Salvador, Brazil. J Med Micobiol 2007; 56: 313-9.

3.- Guerrant R, Van Gilder T, Steiner T, et al: Practice Guidelines for the Management of Infectious Diarrhea. Clinical Infectious Disease 2001; 32: 331-50.
4.- Guarino A, Albano F, Ashkenazi S, et al: ESPGHAN/ ESPID Evidence-Based Guidelines for the Management of Acute Gastroenteritis in Children in Europe Expert Working Group. European Society for Paediatric Gastroenterology, Hepatology, and Nutrition/European Society for Paediatric Infectious Diseases evidence-based guidelines for the management of acute gastroenteritis in children in Europe: executive summary. J Pediatr Gastroenterol Nutr 2008; 46 (5): 619-21.

5.- Korczowski B, Szybist W: Serum procalcitonin and Creactive protein in children with diarrhoea of various etiologies. Acta Paediatr 2004; 93: 169-73.

6.- Thia $K K$-J, Chan E S-Y, Ling $K-L, N g W$-Y, Jacob E, Ooi $C$-J: Role of Procalcitonin in Infectious Gastroenteritis and Inflammatory Bowel Disease. Dig Dis Sci 2008; 53: 2960-8.

7.- Gendrel D, Bohuon C: Procalcitonin as a marker of bacterial infection. Pediatr Infect Dis J 2000; 19: 679-88.

8.- Becker KL, Nylen ES, White JC, Müller B, Snider RH: Procalcitonin and the Calcitonin Gene Family of Peptides in Inflammation, Infection, and Sepsis: A journey from Calcitonin Back to Its Precursors. J Clin Endocrinol Metab 2004; 89 (4): 1512-25.

9.- Subcommittee on acute gastroenteritis and provisional committee on quality improvement. Practice Parameter: The management of acute gastroenteritis in young children. Pediatrics 1996; 97: 424-35.

10.- Alcalá L, Sánchez-Cambronero L, Catalán MP, et al: Comparison of Three Commercial Methods for Rapid Detection of Clostridium difficile Toxins A and B from Fecal Specimens J Clin Microbiol 2008; 46 (11): 38335.

11.- De Wit MA, Koopmans MP, Kortbeek LM, van Leeuwen $N J$, Vinje J, van Duynhoven YT: Etiology of Gastroenteritis in Sentinel General Practices in The Netherlands. Clin Infect Dis 2001; 33: 280-8.

12.- Maltezou HC, Zafiropoulou A, Mavrikou M, et al: Acute diarrhoea in children treated in an outpatient setting in Athens, Greece. J Infect 200143 (2): 122-7.

13.- Finkelstein JA, Schwartz JS, Torrey S, Fleisher GR: Common clinical features as predictors of bacterial diarrhea in infants. Am J Emerg Med 1989; 7: 469-73.

14.- Borgnolo G, Barbone F, Guidobaldi G, Olivo G: Creactive protein in viral and bacterial gastroenteritis in childhood. Acta Paediatr 1996; 85: 670-4. 